\title{
Combining theory and experiment analysis in molten BFS waste heat recovery integrated with coal gasification
}

\author{
Wenjun Duan ${ }^{1, *}$, Yunke $\mathrm{Gao}^{1}$, Qingbo $\mathrm{Yu}^{1}$, and Zhimei Wang ${ }^{2}$ \\ ${ }^{1}$ School of Metallurgy, Northeastern University, No 11, Lane 3, Wenhua Road, He Ping District, Shenyang 110819, Liaoning, People's \\ Republic of China \\ ${ }^{2}$ Shenyang Metrology Testing Institution, No. 43, Shi Ji Road, Hun Nan District, Shenyang, Liaoning, 110179, People’s Republic of \\ China
}

\begin{abstract}
A novel method that a heat recovery system from blast furnace slag integrated with coal gasification reaction to generate syngas was proposed. The motion characteristic and critical velocity of the coal particles in the molten slag were estimated. Meanwhile, the effects of temperature and steam to coal ratio on coal gasification product distribution and gas characterization were discussed. The results showed that the coal particles $(\sim 75 \mu \mathrm{m})$ would break through the bondage of bubbles and transport into molten slag when the velocity of coal particles were above $4.20 \mathrm{~m} \cdot \mathrm{s}^{-1}$ and the diameter of bubbles were less $6 \mathrm{~mm}$. There had higher gasification efficiency, gas yield production and $\mathrm{H}_{2}$ production by this method. The results suggested that the optimal conditions for slag waste heat recovery were achieved at $1623 \mathrm{~K}$ and steam to coal ratio of 2.0. Under these conditions, the gas yield and carbon conversion reached $133.48 \mathrm{~mol} \cdot \mathrm{kg}^{-1}$ and $97.81 \%$, respectively. The proposed method enhanced the coal gasification efficiency and recovered the high quality of molten blast furnace slag waste heat effectively, and had important guidance for industrial manufacture.
\end{abstract}

\section{Introduction}

Nowadays, with the continuous development in China, there was an increasing consideration of energy saving and emission reduction in the traditional industry, especially in the iron and steel industry, as an energy and carbon intensive industry [1-3]. Blast furnace slag (BFS) was one of the main by-products of iron and steel industry. Approximately 0.3 tons of BFS were produced for each ton of steel manufactured. The BFS came out at above $1773 \mathrm{~K}$ and each ton carried about $1.77 \mathrm{GJ}$ of energy [4]. Consequently, about 235 million tons of BFS were produced with energy content of $4.16 \times 10^{8} \mathrm{GJ}$, which was converted into 14.20 million tons standard coal. Therefore, it was of great significance to recover and utilize the high quality waste heat of molten BFS for iron and steel industry.

In recent years, recovering high quality waste heat of slag by chemical method had received widespread attention. Kasai [5] developed a process to promote an endothermic reaction of the mixed gas to produce $\mathrm{H}_{2}$ and $\mathrm{CO}$ using slag waste heat. Purwanto et al [6] designed an experiment to investigate the possibility of decomposing $\mathrm{CH}_{4}-\mathrm{CO}_{2}$ mixture. The experiment integrated sludge $/ \mathrm{CO}_{2}$ gasification by the waste heat of hot slag was explored with the aim of syngas production, waste heat recovery and sewage sludge disposal by Sun [7-10]. The results demonstrated that the total gas yields increased from $0.022 \mathrm{~kg} \cdot \mathrm{kgsludge}^{-1}$ at $773 \mathrm{~K}$ to 0.42 $\mathrm{kg} \cdot \mathrm{kgsludge}^{-1}$ at $1173 \mathrm{~K}$. Zhao et al [11] explored the possibility of combustible gas production from municipal solid waste using hot BFS. The contents of the combustible gas increased with increasing temperature, and the lower calorific value increased rapidly at $873 \mathrm{~K}$ $\sim 1173 \mathrm{~K}$. The volume fraction of $\mathrm{CO}, \mathrm{H}_{2}$ and $\mathrm{CH}_{4}$ at different atmospheres increased in the order $\mathrm{N}_{2}<$ air $<$ steam. Luo et al [12-15] established a continuous moving-bed biomass gasification reactor to recover BFS waste heat. The influences of temperature and particle size of BFS on biomass gasification product distribution and syngas characterization were discussed.

Based on the characterization of molten BFS waste heat and current energy situation of China, Duan et al [16-19] carried on the thorough research of utilizing coal gasification reaction to recover the high temperature and quality waste heat of blast furnace slag. In order to provide some references for the experiment, we conducted thermodynamic analysis and kinetic analysis to obtain the theory optimal operation parameter and most appropriate kinetic model, respectively. In the present paper, the motion state of the coal particles in molten BFS was analyzed. The effects of temperature and steam to coal ratio were investigated, so as to obtain the optimal operation parameters and guide the industrial production.

\footnotetext{
*Corresponding author: duanwenjn@163.com
} 


\section{Method and mechanism}

\subsection{Feedstock}

Datong coal was selected for gasification experiment to recover the slag waste heat. Its compositions and properties were shown in Table 1. The proximate analysis of the sample was conducted using an automatic coal proximate analyzer. The ultimate analysis of the sample was conducted by a CHNS/O Analyzer, Perkin Elmer PR 2400 series II. BFS from an iron and steel company was used in experiments with chemical compositions of 41.21 mass $\% \mathrm{CaO}, 34.38$ mass $\% \mathrm{SiO}_{2}$, 11.05 mass $\% \mathrm{Al}_{2} \mathrm{O}_{3}, 8.22$ mass $\% \mathrm{MgO}, 2.78$ mass \% $\mathrm{Fe}_{2} \mathrm{O}_{3}, 0.35$ mass \% $\mathrm{TiO}_{2}$ and some minor constituents. Its chemical compositions were analyzed by X-ray fluoroscopy.

Table 1 The proximate and ultimate analysis of the Datong coal

\begin{tabular}{cc}
\hline \multicolumn{2}{c}{ Proximate analysis $(w t, \%)$} \\
\hline Moisture & 9.05 \\
Volatile matter & 38.38 \\
Fixed carbon & 38.42 \\
Ash & 14.15 \\
\hline Ultimate analysis $(w t, \%)$ \\
\hline Carbon & 64.53 \\
Hydrogen & 3.75 \\
Nitrogen & 0.96 \\
Sulfur & 0.56 \\
Oxygen & 7.01 \\
\hline
\end{tabular}

\subsection{Experimental apparatus and procedure}

Because of the high temperature with the sharp corrosive property of the molten BFS, a high purity corundum with high corrosion resistance was adopted as the reactor to perform the coal gasification reaction for a long time, as shown in Fig. 1. In the experiment, the height of the molten BFS in the reactor was about $300 \mathrm{~mm}$ to ensure the complete of the gasification reaction. The powder feeder worked and the pulverized coal was carried into the reactor by nitrogen. Meanwhile, the steam was transported into the reactor as the gasification agent to complete the gasification reaction. The production syngas was recorded by gas analyzer, and the powder feeder was closed after the gas composition being stable for $30 \mathrm{~min}$.

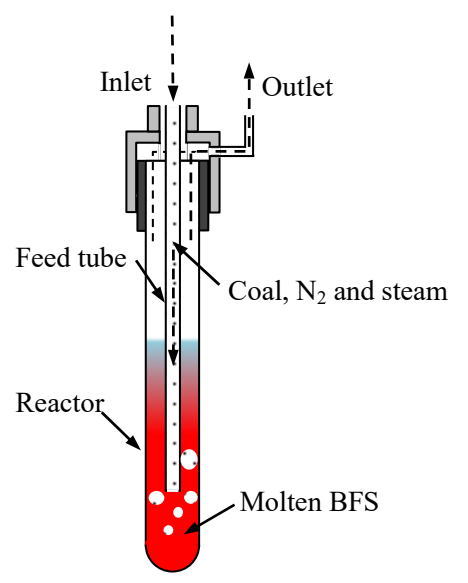

Fig. 1 The schematic diagram of the gasification reactor

\subsection{Gasification mechanism}

The coal gasification reaction was a complex process in which the solid fuels were converted to syngas by partial oxidization. The results were interpreted based on the following reversible chemical reaction simplified which occurred during the gasification reaction in molten BFS.

Boudouard reaction:

$$
\mathrm{C}+\mathrm{CO}_{2} \leftrightharpoons 2 \mathrm{CO} ; \Delta H_{\mathrm{r}}=172 \mathrm{~kJ} / \mathrm{kmol}
$$

Methane formation reaction:

$$
\mathrm{C}+2 \mathrm{H}_{2} \leftrightharpoons \mathrm{CH}_{4} ; \Delta H_{\mathrm{r}}=-75 \mathrm{~kJ} / \mathrm{kmol}
$$

Primary water gas reaction:

$$
\mathrm{C}+\mathrm{H}_{2} \mathrm{O} \leftrightharpoons \mathrm{CO}+\mathrm{H}_{2} ; \Delta H_{\mathrm{r}}=131 \mathrm{~kJ} / \mathrm{kmol}
$$

Methane reforming reaction:

$$
\mathrm{CH}_{4}+\mathrm{H}_{2} \mathrm{O} \leftrightharpoons \mathrm{CO}+3 \mathrm{H}_{2} ; \Delta H_{\mathrm{r}}=206 \mathrm{~kJ} / \mathrm{kmol}
$$

Water gas shift reaction:

$$
\mathrm{CO}+\mathrm{H}_{2} \mathrm{O} \leftrightharpoons \mathrm{CO}_{2}+\mathrm{H}_{2} ; \Delta H_{\mathrm{r}}=-41 \mathrm{~kJ} / \mathrm{kmol}
$$

Meanwhile, there were some specific reactions occurred when the BFS existed in the process of coal gasification.

$$
\begin{aligned}
& \mathrm{CaO}+1 / 2 \mathrm{O}_{2} \rightarrow \mathrm{CaO}_{2} \\
& \mathrm{CaO}_{2}+\mathrm{C} \rightarrow \mathrm{CaO}+\mathrm{CO} \\
& \mathrm{Fe}_{\mathrm{m}} \mathrm{O}_{\mathrm{n}}+\mathrm{CO}_{2} \rightarrow \mathrm{Fe}_{\mathrm{m}} \mathrm{O}_{\mathrm{n}+1}+\mathrm{CO} \\
& \mathrm{Fe}_{\mathrm{m}} \mathrm{O}_{\mathrm{n}+1}+\mathrm{C} \rightarrow \mathrm{Fe}_{\mathrm{m}} \mathrm{O}_{\mathrm{n}}+\mathrm{CO}
\end{aligned}
$$

\section{Results and discussions}

\subsection{Motion state of the coal particles}

The coal particles were transported into the molten BFS by $\mathrm{N}_{2}$ and gasification agent stream. In molten slag, coal particles mainly existed in four forms, as shown in Fig. 2. Firstly, the coal particles were wrapped completely in the bubble and isolated with the molten BFS (State A). Then, with the relative motion between the coal particles and bubble, some coal particles were stayed at the boundary surface of the slag and gas (State B). Meanwhile, some coal particles with a certain speed could break through all restraint of the gas into molten slag (State C). Finally, the residual coal particles were captured by slag when these were gradually rising to the surface of molten slag (State D). Therefore, master the motion characteristic and critical velocity of the coal particles in the molten BFS was necessary.

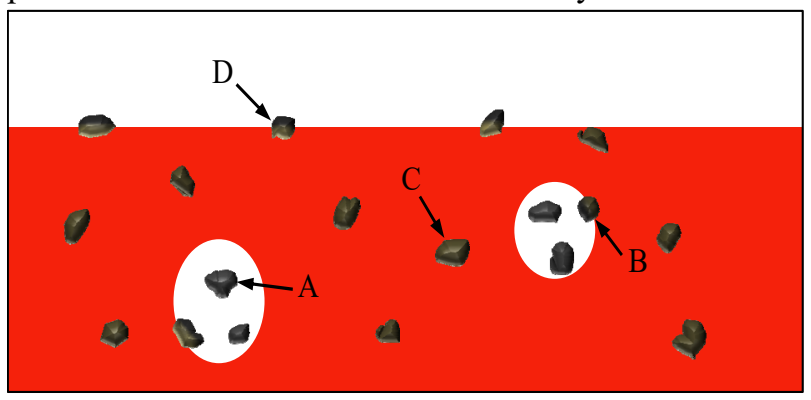

Fig. 2 The existence form of the coal particles in molten slag

Three assumptions were proposed to calculate the velocity of coal particles: 
(1) Coal particles were spherical;

(2) Ignore the reaction between coal and agent, and the coal particles diameter and density remained unchanged;

(3) The gas temperature was consistent with molten slag temperature.

Based on results of Guo [20], the velocity vs. time of the coal particles was expressed as followed:

$$
\frac{d u_{p}}{d t}=\frac{g\left(\gamma_{p}+\gamma_{g}\right)}{\gamma_{p}}-\varphi C_{s} \frac{3 u_{p}}{4 d_{p}}
$$

where, $u_{p}$ was the coal particles velocity, $\mathrm{m} \cdot \mathrm{s}^{-1} ; \gamma_{p}$ and $\gamma_{g}$ were the density of the coal particles and bubble, respectively, $\mathrm{kg} \cdot \mathrm{m}^{-3} ; C_{s}$ was the friction coefficient; $\varphi$ was the surface roughness of the coal particles, $\varphi=1 ; d_{p}$ was the coal diameter, $\mathrm{m}$.

The velocity vs. distance of the coal particles was expressed as followed:

$$
u=\frac{d y}{d t}
$$

where, $y$ was the motion distance, $\mathrm{m}$.

The critical velocity of the coal particles in molten BFS was expressed as followed [20]:

$$
u_{b}^{*}=\left(\frac{12 \sigma_{s} \cos \theta}{\gamma_{p} d_{p}}\right)^{\frac{1}{2}}
$$

where, $u_{b}{ }^{*}$ was the critical velocity of the coal particles in molten BFS, $\mathrm{m} \cdot \mathrm{s}^{-1} ; \sigma_{s}$ was the surface tension of the molten slag, $\mathrm{N} \cdot \mathrm{m}^{-1}$.

It could be seen from Fig. 3, the coal particles could across the bubble $(d<6 \mathrm{~mm})$ when the velocity and diameter of coal particles were $4.20 \mathrm{~m} \cdot \mathrm{s}^{-1}$ and $75 \mu \mathrm{m}$, respectively. The coal particles gasification reaction would proceed in the bubble completely when the bubble diameter was greater than $6 \mathrm{~mm}$.

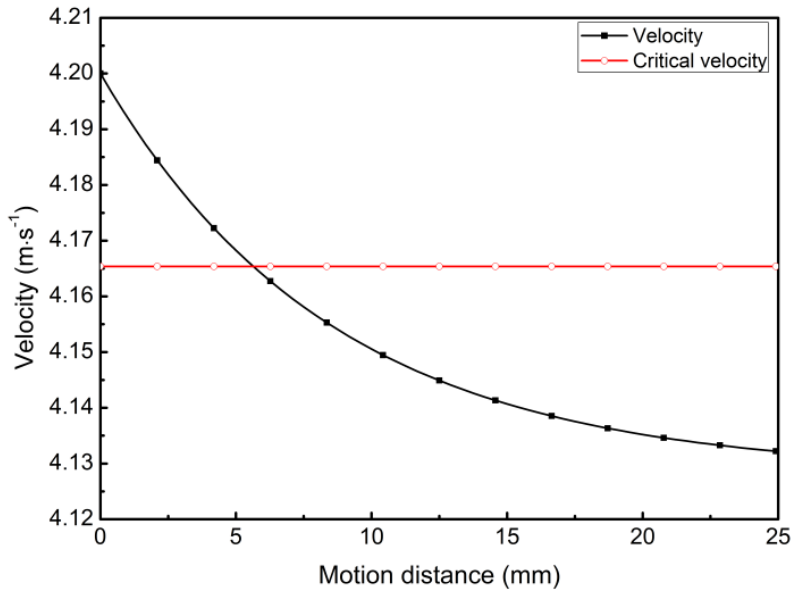

Fig. 3 Coal particles critical velocity vs. motion distance

\subsection{Effect of temperature}

To explore the effect of reaction temperature, we performed experiments at $1573 \mathrm{~K}, 1623 \mathrm{~K}, 1673 \mathrm{~K}, 1723$ $\mathrm{K}$ and $1773 \mathrm{~K}$. As shown in Fig. 4(a), the fraction of $\mathrm{H}_{2}$ was holding steady, which was higher than $60 \%$. The fraction of $\mathrm{CO}$ and $\mathrm{CO}_{2}$ had a converse trend. It could be seen from Fig. 4(b), the gas yield of the coal gasification reaction reached maximum at the range of $1623 \mathrm{~K}$
$1673 \mathrm{~K}$. The carbon conversion increased with the temperature increasing. It was because that higher temperature could provide more favorable conditions for thermal cracking and steam reforming of carbon making the carbon conversion dramatically increased. Meanwhile, the cracking of volatile matter was accelerated at high temperature, which was another reason for improving the gasification performance [21]. Although the higher gasification temperature was more beneficial to the gasification, it was necessary to recover the waste heat of BFS as much as possible. Therefore, combining the condition of gasification and waste heat recovery, the optimal temperature of the gasification reaction was $1623 \mathrm{~K}$.
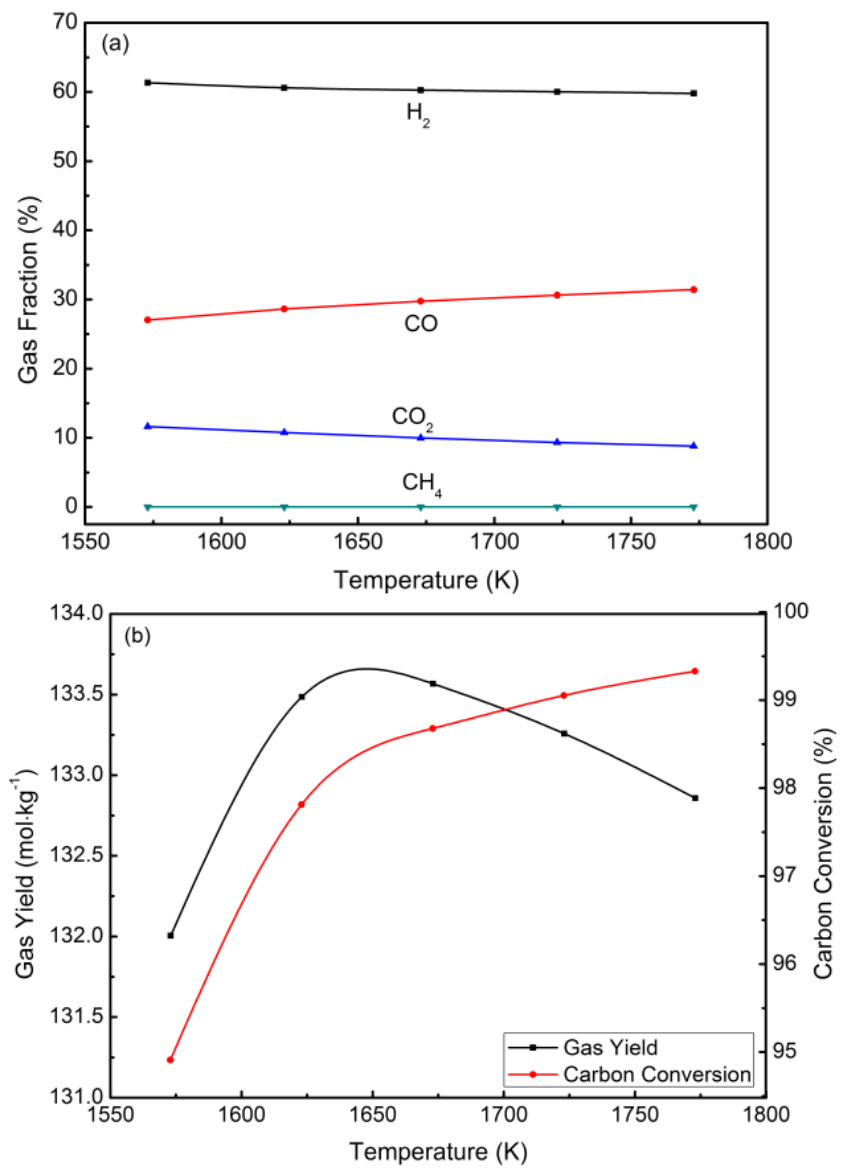

Fig. 4 The effect of temperature on coal gasification reaction (steam to coal ratio $=2.0$ )

\subsection{Effect of steam to coal ratio}

Fig. 5 showed the changing condition of Datong coal gasification in molten BFS. It could be seen from the pictures, $\mathrm{H}_{2}$ fraction increased slowly with the increasing of steam to coal ratio, but the changing of $\mathrm{CO}$ was contrasted with $\mathrm{H}_{2}$. Meanwhile, both gas production and carbon conversion increased dramatically firstly, and then increased slightly. Therefore, it was benefited to the gasification reaction with the increasing of steam to coal ratio. At the steam to coal ratio of 2.0, the gas yield and carbon conversion reached $133.48 \mathrm{~mol} \cdot \mathrm{kg}^{-1}$ and $97.81 \%$, respectively. After that, extra steam was introduced than necessary for gasification, which caused waste of the high quality BFS heat [22]. For the purpose of 
recovering slag waste heat and proceeding the coal gasification extensively, the optimal steam to coal ratio of coal gasification reaction was 2.0.
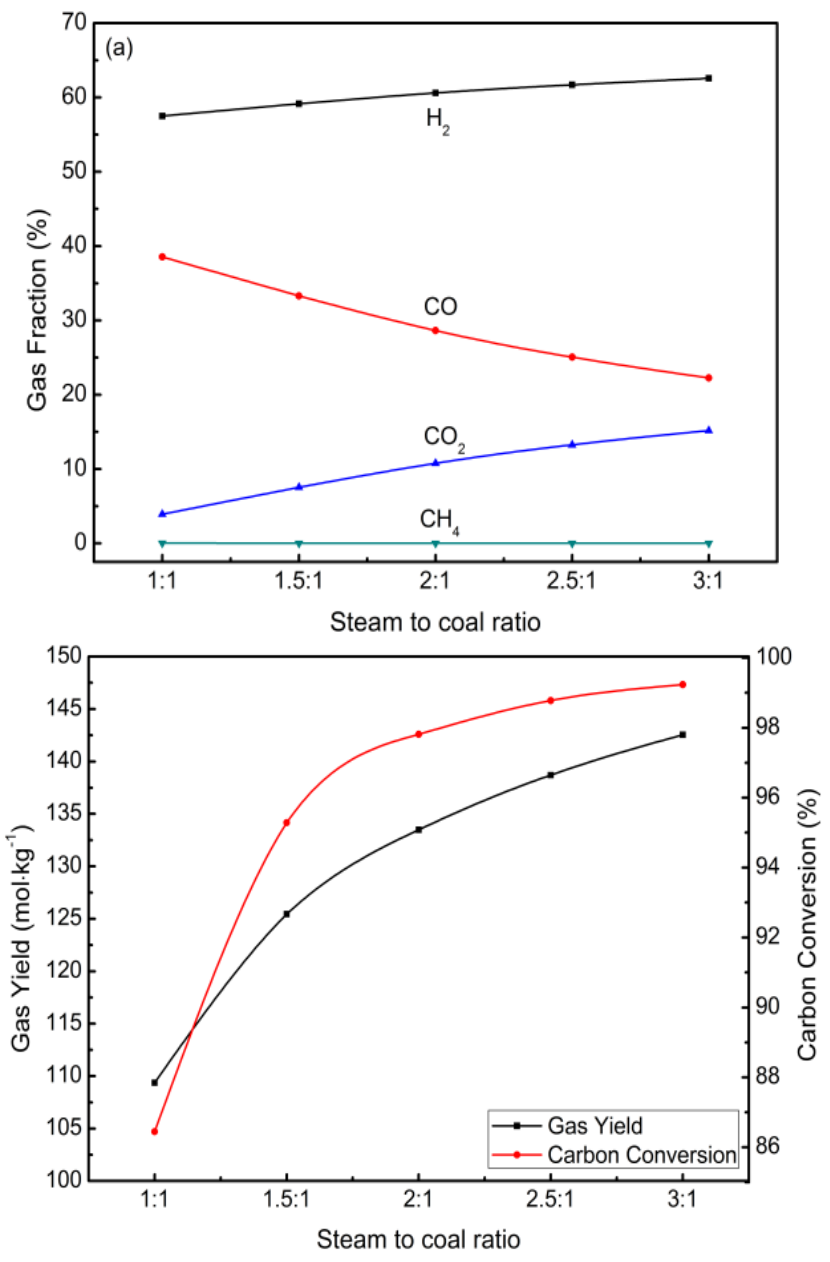

Fig. 5 The effect of steam to coal ratio on coal gasification reaction $($ Temperature $=1623 \mathrm{~K})$

\section{CONCLUSIONS}

In this paper, a novel experiment of coal gasification reaction by molten BFS as heat carrier for waste heat utilization and syngas production has been presented. The motion states of coal particles in molten slag could be divided into four states, which mainly depended on the velocity of coal particle. The coal particles would break through the bondage of bubbles and transport into molten slag when the velocity of coal particles higher than critical velocity. Based on the theoretical calculation, the coal particles could across the bubbles $(d<6 \mathrm{~mm})$ when the velocity and diameter of coal particles were $4.20 \mathrm{~m} \cdot \mathrm{s}^{-1}$ and $75 \mu \mathrm{m}$, respectively. Meanwhile, the effect of temperature and steam to coal ratio were discussed in detail. The carbon conversions were higher than $95 \%$ in the temperature range of 1573 $\mathrm{K} \sim 1773 \mathrm{~K}$. In order to recover the waste heat of slag as much as possible, we set the optimal temperature of the gasification reaction at $1623 \mathrm{~K}$. Increasing the steam to coal ratio could led to the increasing of gas yield and carbon conversion, while the extra steam would consume more energy. Therefore, the optimal steam to coal ratio of the coal gasification reaction in molten BFS was 2.0.

\section{ACKNOWLEDGEMENTS}

This research was supposed by Th National Natural Science Foundation of China (51704071), The National Postdoctoral Program for Innovative Talents (BX201600028), The Fundamental Research Funds for the Central Universities (N170204016).

\section{REFERENCES}

[1] Y.Q. Sun, Z.T. Zhang, L.L. Liu, X.D. Wang, Int. J. Hydrogen. Energ. 41, 11 (2016).

[2] Q. Zhang, X.Y. Zhao, H.Y. Lu, T.J. Ni, Y. Li, Appl. Energ. 191, 19 (2017).

[3] Q. Zhang, X. Jin, Y.J. Wang, W. Zhang, Appl. Energ. 209, 15 (2018).

[4] R. Dhirhi, K. Prasad, A.K. Shukla, S, Sarkar, T. Renganathan, S. Pushpavanam, M. Kaza, Appl. Therm. Eng. 107, 9 (2016).

[5] E. Kasai, T. Kitajima, T. Akiyama, J. Yagi, F. Saito, ISIJ. Int. 37, 6 (1997).

[6] H. Purwanto, T. Akiyama, Int. J. Hydrogen. Energ. 31, 5 (2006).

[7] Y.Q. Sun, Z.T. Zhang, L.L. Liu, X.D. Wang, Bioresource. Technol. 181, 9 (2015).

[8] Y.Q. Sun, Z.T. Zhang, L.L. Liu, X.D. Wang, Bioresource. Technol. 198, 8 (2015).

[9] Y.Q. Sun, J.J. Chen, Z.T. Zhang, Energ. 167, 10 (2019).

[10] Y.Q. Sun, S. Seetharaman, Z.T. Zhang, Energ. 149, 12 (2018).

[11] L.M. Zhao, H. Wang, S. Qing, H.L. Liu, J. Nat. Gas. Chem. 19, 6 (2010).

[12] S.Y. Luo, Y.M. Zhou, C.J. Yi, Int. J. Hydrogen. Energ. 37, 5 (2012).

[13] S.Y. Luo, Y. Feng, Energ. 113, 845-851 (2016).

[14] S.Y. Luo, C.J. Yi, Y.M. Zhou, Renew. Energ. 50, 5 (2013).

[15] S.Y. Luo, J. Fu, Y.M. Zhou, C.J. Yi, Renew. Energ. 101, 7 (2017).

[16] W.J. Duan, Q.B. Yu, H.Q. Xie, Q. Qin, Z.L. Zuo, Int. J. Hydrogen. Energ. 39, 9 (2014).

[17] W.J. Duan, Q.B. Yu, K. Wang, Q. Qin, L.M. Hou, X. Yao, T.W. Wu, Energ. Convers. Manage. 100, 7 (2015).

[18] W.J. Duan, Q.B. Yu, Z.M. Wang, J.X. Liu, Q. Qin, Energ. 142, 10 (2018).

[19] W.J. Duan, Y.K. Gao, Q.B. Yu, T.W. Wu, Z.M. Wang, Energ. 183, 11 (2019).

[20] Z.C. Guo, D.G. Wang, Z.H. Xu, Eng. Chem. Metall. 13, 7 (1992).

[21] R.P. Wang, Q.X. Hua, P. Lu, W.J. Li, S.K. Wang, Y. Chi, J.H. Yan, Int. J. Hydrogen. Energ. 40, 8 
(2015).

[22] K. Sandeep, S. Dasappa, Int. J. Hydrogen. Energ. 39, 11 (2014) 